\title{
Periodontal characteristics of diabetic patients with tooth mobility
}

\author{
Patrick I. Ojehanon, Clement C. Azodo, Paul Erhabor ${ }^{1}$, Vera Orhue ${ }^{1}$ \\ Department of Periodontics, University of Benin, ${ }^{1}$ Department of Periodontics, University of Benin Teaching Hospital, Benin City, \\ Edo State, Nigeria
}

Abstract

Objective: To determine the periodontal characteristics of diabetic patients with tooth mobility attending the Periodontology Clinic of University of Benin Teaching Hospital (UBTH), Benin City, Nigeria.

Materials and Methods: This cross-sectional observational study was conducted among diabetic patients with tooth mobility in the Periodontology Clinic in UBTH, Benin City, Nigeria. The indices recorded for the participants were gingival index, community periodontal index of treatment need, and Miller'sindex for tooth mobility.

Results: A total of 54 participants who met the inclusion criteria were approached, but only 49 of them consented and participated in this study giving a 90.7\% recruitment rate. The age range and mean age of the participants were $42-84$ years and $63.84 \pm 1.31$ years, respectively. The self-reported age of diagnosis was between 41 and 70 years with a mean age of $56.22 \pm 6.88$ years. About two-thirds $(67.3 \%)$ of the participants were males. Less than half (38.8\%) of patients were visiting the dentist for the first time. Mandibular arch housed about two-thirds (64.9\%) of the mobile teeth and mandibular left quadrant housed about one-third of (34.5\%) the mobile teeth. Central incisor $(42.3 \%)$ constituted the most mobile teeth followed by the first molar (28.9\%). A total of $17.0 \%$ of the mobile teeth were Miller's Grade 3 mobility. More than one-third $(28.5 \%$ ) (code $3=26.5 \%$, code $4=2.0 \%$ ) of the participants had periodontal pockets. More than half $(52.7 \%)$ of participants had probing pocket depth of $5 \mathrm{~mm}$ and above. The gingival score which had mean as $1.60 \pm 0.08$ was significantly associated with age of the participants. The mean probing depth was $4.86 \pm 0.21 \mathrm{~mm}$. The probing depth was significant with age and duration of diabetes mellitus (DM) of the participants.

Conclusion: Data from this study revealed that age of diagnosis of diabetes with tooth mobility was higher than previously reported. The most mobile teeth and earliest teeth to become mobile were the mandibular incisors, and Grade 1 severity constituted the majority. DM with tooth mobility exhibited gingival score and probing depth that had a variable significant association with demographic characteristics.

Keywords: Dentition, diabetes mellitus, periodontal diseases, tooth mobility

Address for correspondence: Dr. Clement C. Azodo, Department of Periodontics, Prof. Ejide Dental Complex, University of Benin Teaching Hospital, P.M.B. 1111, Ugbowo, Benin City, Edo State, Nigeria.

E-mail: clementazodo@yahoo.com

Received: 14.01.2017, Accepted: 02.04.2017

\begin{tabular}{|l|l|}
\hline \multicolumn{2}{|c|}{ Access this article online } \\
\hline Quick Response Code: & Website: \\
\hline & www.joshd.net \\
\cline { 2 - 3 } & DOI: \\
& 10.4103/joshd.J_Soc_Health_ \\
\hline
\end{tabular}

This is an open access article distributed under the terms of the Creative Commons Attribution-NonCommercial-ShareAlike 3.0 License, which allows others to remix, tweak, and build upon the work non-commercially, as long as the author is credited and the new creations are licensed under the identical terms.

For reprints contact: reprints@medknow.com

How to cite this article: Ojehanon PI, Azodo CC, Erhabor P, Orhue V. Periodontal characteristics of diabetic patients with tooth mobility. J Soc Health Diabetes 2017;5:94-9. 


\section{INTRODUCTION}

Diabetes mellitus (DM) is a clinical syndrome characterized by hyperglycemia due to an absolute or relative deficiency of insulin. ${ }^{[1]}$ It results in abnormality in the metabolism of carbohydrate, fat, and protein resulting in end-organ damage, i.e., vascular, renal, ocular, neurologic, and periodontal complications. The estimated prevalence of diabetes among adults worldwide in 2010 was 285 million $(6.4 \%)$ and is expected to rise to around 439 million $(7.7 \%)$ by 2030 with prevalence is predicted rise being much greater in developing than developed countries. ${ }^{[2]}$

The prevalence of DM in the population of African communities is on the increase due to lifestyle changes. The prevalence of DM in South Western Nigeria is $4.76 \%$ with $2.38 \%$ as undiagnosed DM. ${ }^{[3]}$ The prevalence of undiagnosed DM in the outpatient dental clinic of University of Benin Teaching Hospital (UBTH) and University College Hospital is $4.5 \%{ }^{[4]}$ and $4.4 \%,{ }^{[5]}$ respectively.

The prevalence of periodontal disease in patients with diabetes is reported to be higher than their nondiabetic counterparts with poorly controlled diabetes having worse periodontal parameters than well-controlled diabetes. ${ }^{[6,7]}$ These periodontal parameters are in the form of increased bleeding on probing, greater attachment and alveolar bone loss, increased tooth mobility, and eventual tooth loss. ${ }^{[8]}$ The worse periodontal status is related to more bacterial proliferation as a consequence of diminished primary defense against bacterial pathogens which are resultant effects of impaired chemotaxis, defective phagocytosis, and impaired adherence of polymorphonuclear leukocytes (PMNs) and macrophages. ${ }^{\left[{ }^{[0]}\right.}$ The hyperglycemia leads to the formation of advanced glycation end products which cross-link collagen making them less soluble and less likely to be repaired or replaced. Furthermore, the increased serum triglyceride level in uncontrolled patients with diabetes seems to be related to greater attachment loss and probing depths.

Periodontitis as a manifestation of systemic disease causes the destruction of both soft and hard tissue components of tooth-supporting structure leading to tooth mobility ${ }^{[10]}$ Report on tooth mobility revealed that DM as a major systemic disease among patients in Specialist Periodontology Clinic in Nigeria. ${ }^{[11]}$ Tooth mobility is the degree of displacement of the tooth in its socket on the application of force and is considered an important clinical feature in the diagnosis of periodontal diseases.
Tooth mobility is usually graded into Grade 1, 2, and 3 in periodontal disease management using Miller's tooth mobility index because it has bearing on the choice of treatment and prognosis. ${ }^{[12]}$ The mechanism through which periodontitis cause tooth mobility includes inflammatory disruption of the periodontal tissues, widening of the periodontal ligament, attachment loss, alveolar bone loss, and secondary occlusal trauma. ${ }^{[13]}$ The continued movement of mobile teeth during oral function further damages the periodontium accelerating the disease process and thereby leading to tooth loss. ${ }^{[14]}$ Tooth mobility causes occlusal instability, masticatory disturbances, esthetic challenges, and impaired quality of life. The masticatory disturbance may result in eating impairment, dietary selection restriction, and poor nutritional status which will worsen their glycemic control. The objective of this study was to determine the periodontal characteristics of diabetic patients with tooth mobility attending the Periodontology Clinic of UBTH, Benin City, Nigeria.

\section{MATERIALS AND METHODS}

\section{Ethical considerations}

The protocol for this research was reviewed and approval granted by the Ethics and Research Committee of the UBTH. Written informed consent was obtained from the participants.

\section{Study setting/design}

This cross-sectional observational study was conducted among diabetic patients with tooth mobility attending the Periodontology Clinic of the UBTH, Benin City, Nigeria, between January 2014 and December 2015.

\section{Sample size/sampling}

The convenient sampling technique was employed to recruit 54 participants which exceeded the minimum sample size of 45 calculated using Cochran's formula for epidemiological studies. ${ }^{[15]} n=z^{2} p(1-p) / d^{2}$ where $n=$ sample size, $z=q$-statistics for a level of confidence (set at 1.96 corresponding to $95.0 \%$ confidence level), $P=0.967$ (96.7\%), which is the prevalence of periodontal disease among urban and rural populations in Edo State, Nigeria, ${ }^{[16]} q=1-p$ and $d=$ degree of accuracy $\operatorname{desired}($ error margin $)=5 \%(0.05)$.

\section{Inclusion criteria}

The inclusion criteria were known diabetic patients with tooth mobility that consented to participate in the study.

\section{Exclusion criteria}

Smoking, handicap, current use of antibiotics or mouthwashes, dental caries, and presence of any 
underlying condition would have served as possible risk factors (secondary etiological factors) for periodontal diseases and would have been significant confounders in this study and therefore were excluded from the study. Patients wearing dental appliances (prosthetic and orthodontic) and those whom consent could not be obtained were also excluded from the study.

\section{Data collection}

Demographic details were recorded followed by examination by the calibrated researcher. Patients with diabetes with varying degrees of tooth mobility assessed using Miller's tooth mobility index were recruited, and subsequent evaluation done were gingival status using gingival index (GI), periodontal status using community periodontal index of treatment need (CPITN), and periodontal depth by probing depth. The scoring of tooth mobility done by assessing all the teeth in the patient's mouth by moving each tooth between the ends of two metallic instruments was as follows:

- Score 0: No detectable mobility

- Score 1: Distinguishable tooth mobility from the normal

- Score 2: Crown of tooth moves more than $1 \mathrm{~mm}$ in a lateral direction

- Score 3: Movement of more than $1 \mathrm{~mm}$ in a lateral direction, and the ability to depress the tooth in a vertical direction.

The GI was assessed by visually observing the gingiva for color, size, ulceration, and spontaneous bleeding as well as probing gently along the wall of soft tissue of the gingival sulcus. The scoring was done for the mesial, buccal, distal, and lingual gingival tissues separately on a scale of $0-3$ as follows:

- $0=$ Normal gingiva

- 1 = Mild inflammation - slight change in color and slight edema but no bleeding on probing

- 2 = Moderate inflammation - redness, edema and glazing, bleeding on probing

- 3 = Severe inflammation - marked redness and edema, ulceration with a tendency to spontaneous bleeding.

For each tooth, the scores of the four areas of the tooth were summed and divided by four to give the GI for the tooth. The GI of the individual was obtained by adding the values of each tooth and dividing by the number of teeth examined.

CPITN was used to assess the periodontal status. The dentition was divided into 6 sextants: upper right (17-14), upper anterior (13-23), upper left (24-27), lower right
(47-44), lower anterior (43-33), and lower left (34-37). All teeth in each sextant were examined, with the exception of third molars. For a sextant to qualify for recording, it must contain at least two teeth. Where only one tooth was present in a sextant, the score for that tooth was included in the recording for the adjacent sextant.

- Code 0: Given to the sextant if there are no pockets exceeding $3 \mathrm{~mm}$ in depth (colored area remains totally visible), no calculus or overhangs of fillings, and no bleeding after gentle probing

- Code 1: Given to the sextant if there are no pockets exceeding $3 \mathrm{~mm}$ in depth (colored area remains totally visible) and no calculus or overhangs of fillings but bleeding occurs after gentle probing

- Code 2: Given to the sextant if there are no pockets exceeding $3 \mathrm{~mm}$ in depth (colored area remains totally visible) but dental calculus or other plaque retention factors are seen at or recognized underneath the gingival margin

- Code 3: Given to the sextant if the color-coded area of the probe remains partially visible when inserted into the deepest pocket indicating pocket depth between 3.5 and $5.5 \mathrm{~mm}$

- Code 4: Given to the sextant if at one or more teeth, the color-coded area of the WHO probe disappears into the inflamed pocket indicating pocket depth of $6 \mathrm{~mm}$ or more.

\section{Data analysis}

The data obtained were subjected to the descriptive statistics in the form of frequency, percentages, cross-tabulations, means, standard error of mean, and standard deviation using IBM SPSS version 20.0 (Armonk, NY: IBM Corp).

\section{RESULTS}

A total of 54 participants who met the inclusion criteria were approached, but only 49 of them consented and participated in this study giving a $90.7 \%$ recruitment rate. The age range and mean age of the participants were 42-84 years and $63.84 \pm 1.31$ years, respectively. More than half $(53.1 \%)$ of the participants were middle-aged adults while the remaining $46.9 \%$ were elderly. The self-reported age of diagnosis was between 41 and 70 years with a mean age of $56.22 \pm 6.88$ years and modal age of 56 years. About three-tenth $(30.6 \%)$ of the participants had suffered diabetes for more than 10 years. About two-thirds $(67.3 \%)$ of the participants were males. One out of seven participants $(14.3 \%$ ) had nonformal education and about one-third $(32.7 \%)$ of the participants had tertiary education [Table 1]. Less than half $(38.8 \%)$ of patients were visiting the dentist for the first time. A total 
of $60 \%$ of participants that had visited dentist previously had scaling and polishing. Mandibular arch housed about two-thirds $(64.9 \%)$ of the mobile teeth and mandibular left quadrant housed about one-third of $(34.5 \%)$ of the mobile teeth. Central incisor (42.3\%) constituted the most mobile teeth followed by the first molar $(28.9 \%)$ [Table 2]. Nearly half $(45.9 \%)$ of the mobile teeth were Miller's Grade 1 mobility and $17.0 \%$ were Grade 3 mobility [Table 3]. More than one-third (28.5\%) (code $3=26.5 \%$ and code $4=2.0 \%$ ) of the participants had pockets [Table 4]. More than half $(52.7 \%)$ of the participants had probing pocket depth of $5 \mathrm{~mm}$ and above. The earliest tooth in the dentition to become mobile among the participants was mandibular left central incisor followed by right central incisor. The gingival score which had a mean as $1.60 \pm 0.08$ was significantly associated with age of the participants. The mean probing depth was $4.86 \pm 0.21 \mathrm{~mm}$. The probing depth was significantly associated with age and duration of DM of the participants [Table 5].

\section{DISCUSSION}

The pattern of tooth mobility assessed in this study using Miller's tooth mobility index revealed that a total of 194 teeth were mobile with Grade 1 constituting the majority (45.9\%). Grade I mobility is easily treatable by ensured proper diabetic control by their physician, performing local periodontal treatment with or without occlusal adjustment and reinforced home plaque control. Reports of increased alveolar bone loss in patients with diabetes compared to individuals without diabetes ${ }^{[17,18]}$ underscore the weakening of tooth support, thereby manifesting as tooth/teeth mobility. The most severe mobility (Grade 3 ) which is treated by tooth extraction constituted $17.0 \%$ which uniquely qualify diabetes as a major cause of tooth mortality in a population that prefers symptomatic to preventive dental attendance. It has been cited that the periodontal reasons for tooth loss are mainly mobility followed by furcation involvement. ${ }^{[19]}$ The proportion of severe mobility in this study highlights the need for increased awareness of the relationship between DM and periodontal disease and promoting interdisciplinary management of DM among periodontologists and diabetologists. Although a report on the knowledge of the relationship between DM and periodontal diseases revealed major gap in knowledge of the relationship as well as a poor appreciation of the need for a collaborative management of patient with diabetes by medical and dental practitioners, more effort should be geared into improving the knowledge and putting the gained knowledge into practice for the optimal care of the patients with diabetes. ${ }^{[20]}$
Table 1: Demographic characteristics of the participants

\begin{tabular}{lc}
\hline Characteristics & Frequency, $n(\%)$ \\
\hline Age (years) & \\
$41-64$ & $26(53.1)$ \\
$65-84$ & $23(46.9)$ \\
Gender & \\
Male & $33(67.3)$ \\
Female & $16(32.7)$ \\
Educational attainment & \\
Nonformal & $7(14.3)$ \\
Primary & $11(22.4)$ \\
Secondary & $15(30.6)$ \\
Tertiary & $16(32.7)$ \\
Duration of diabetes (years) & \\
0-10 & $34(69.4)$ \\
$11-22$ & $15(30.6)$ \\
Dental clinic attendance & \\
First-time attendee & $19(38.8)$ \\
Previous attendee & $30(61.2)$ \\
Previous treatments & \\
S and P & $11(22.4)$ \\
Extraction & $11(22.4)$ \\
Filling & $1(2.0)$ \\
S and P + extraction & $3(6.1)$ \\
S and P + filling & $4(08.2)$ \\
No treatment & $19(38.8)$ \\
Total & $49(100.0)$ \\
\hline
\end{tabular}

Table 2: Distribution of mobile teeth according to quadrant of mouth among the participants

\begin{tabular}{lcccccc}
\hline \multirow{2}{*}{$\begin{array}{l}\text { Tooth } \\
\text { type }\end{array}$} & \multicolumn{2}{c}{ Maxillary } & & \multicolumn{2}{c}{ Mandibular } & Total \\
\cline { 2 - 3 } & Right, & Left, & & Left, & Right, & \\
\hline 1 & $n(\%)$ & $n(\%)$ & & $n(\%)$ & $n(\%)$ & \\
2 & $2(5.7)$ & 0 & & $40(59.7)$ & $40(67.8)$ & $82(42.3)$ \\
3 & 0 & 0 & $19(28.4)$ & $16(27.1)$ & $35(18.0)$ \\
4 & 0 & 0 & $1(1.5)$ & 0 & $1(0.5)$ \\
5 & 0 & 0 & 0 & 0 & 0 \\
6 & 0 & $1(3.0)$ & 0 & $1(1.7)$ & $2(1.0)$ \\
7 & $24(68.6)$ & $27(81.8)$ & & $5(7.5)$ & 0 & $56(28.9)$ \\
8 & $9(25.7)$ & $5(15.2)$ & & $2(3.0)$ & $2(3.4)$ & $18(9.3)$ \\
Total & 0 & 0 & & 0 & 0 & 0 \\
\hline & $35(18.0)$ & $33(17.0)$ & $67(34.5)$ & $59(30.4)$ & $194(100.0)$ \\
\hline
\end{tabular}

1: Central incisor, 2: Lateral incisor, 3: Canine, 4: First premolar,

5: Second premolar, 6: First molar, 7: Second molar, 8: Third molar

In this study, the most mobile teeth and earliest teeth to become mobile were the mandibular incisors, and this could be related to short length of their roots. The pattern of tooth mobility in this study bears major similarities and a minor difference with a report of Arowojolu ${ }^{[21]}$ among Nigerians seeking periodontal health care. In this study, the sequence was lower incisor, upper first molar, upper second molar, lower first and second molar, upper incisor, premolar, and canine, whereas Arowojolu $^{[21]}$ reported lower incisors, upper incisors, upper first molars, upper second molars, lower first and second molar, the premolars, and the canines. This pattern of tooth mobility also bears some similarities and differences with the pattern of periodontal tooth loss. Jaafar et al. ${ }^{[22]}$ and Sayegh et al. ${ }^{[23]}$ reported the greater proportion of anterior teeth loss due to periodontal 
Table 3: Severity of teeth mobility among the participants

\begin{tabular}{lcccccccccccccccc}
\hline Mobility grade & \multicolumn{10}{c}{ Mobility grade } \\
\cline { 2 - 3 } & 11 & 16 & 107 & 25 & 26 & 27 & 31 & 32 & 33 & 36 & 37 & 41 & 42 & 45 & 47 & Total \\
\hline 1 & 0 & 4 & 0 & 1 & 5 & 1 & 27 & 12 & 1 & 1 & 1 & 26 & 9 & 1 & 0 & $89(45.9)$ \\
2 & 0 & 12 & 3 & 0 & 18 & 3 & 11 & 7 & 0 & 1 & 0 & 9 & 7 & 0 & 1 & $72(37.1)$ \\
3 & 2 & 8 & 6 & 0 & 4 & 1 & 2 & 0 & 0 & 3 & 1 & 5 & 0 & 0 & 1 & $33(17.0)$ \\
Total & 2 & 24 & 9 & 1 & 27 & 5 & 40 & 19 & 1 & 5 & 24 & 0 & 16 & 1 & 2 & $194(100.0)$
\end{tabular}

Table 4: Periodontal status of the participants

\begin{tabular}{|c|c|c|c|c|c|c|c|c|c|}
\hline \multirow[t]{2}{*}{ CPITN } & \multicolumn{2}{|c|}{ Age (years) } & \multicolumn{2}{|c|}{ Gender } & \multicolumn{2}{|c|}{ Attendance } & \multicolumn{3}{|c|}{ Duration of DM (years) } \\
\hline & Middle & Elderly & Male & Female & First & Previous & $0-10$ & $11-22$ & Total \\
\hline 0 & $1(3.8)$ & $3(13.0)$ & $3(9.1)$ & $1(6.3)$ & $2(10.5)$ & $2(6.7)$ & $2(5.9)$ & $2(13.3)$ & $4(8.2)$ \\
\hline 1 & 7 (26.9) & $1(4.3)$ & $5(15.2)$ & $3(18.8)$ & $2(10.5)$ & $6(20.0)$ & $7(20.6)$ & $1(6.7)$ & $8(16.3)$ \\
\hline 2 & $11(42.3)$ & $12(52.2)$ & $15(45.5)$ & $8(50.0)$ & $9(47.4)$ & $14(46.7)$ & $16(47.1)$ & $7(46.7)$ & $23(46.9)$ \\
\hline 3 & $6(23.1)$ & $7(30.4)$ & 9 (27.3) & $4(25.0)$ & $6(31.6)$ & 7 (23.3) & $9(26.5)$ & $4(26.7)$ & $13(26.5)$ \\
\hline 4 & $1(3.8)$ & 0 & $1(3.0)$ & 0 & 0 & $1(3.3)$ & 0 & $1(6.7)$ & $1(2.0)$ \\
\hline
\end{tabular}

DM: Diabetes mellitus, CPITN: Community periodontal index of treatment need

Table 5: Mean gingival scores and probing depth among the participants

\begin{tabular}{lcc}
\hline Characteristics & Gingival score $(\mathrm{mm})$ & Probing depth $(\mathrm{mm})$ \\
\hline Age (years) & & \\
$41-64$ & $1.42 \pm 0.12$ & $4.39 \pm 0.31$ \\
$65-84$ & $1.82 \pm 0.08$ & $5.32 \pm 0.25$ \\
$P$ & 0.010 & 0.027 \\
Gender & & \\
Male & $1.68 \pm 0.09$ & $5.06 \pm 0.23$ \\
Female & $1.44 \pm 0.15$ & $4.42 \pm 0.43$ \\
$P$ & 0.168 & 0.160 \\
Duration of DM (years) & & \\
$0-10$ & $1.55 \pm 0.10$ & $4.66 \pm 0.19$ \\
$11-22$ & $1.71 \pm 0.11$ & $5.23 \pm 0.50$ \\
$P$ & 0.372 & 0.203 \\
First & $1.67 \pm 0.11$ & $4.78 \pm 0.33$ \\
Second & $1.56 \pm 0.11$ & $4.91 \pm 0.28$ \\
$P$ & 0.488 & 0.769 \\
\hline
\end{tabular}

DM: Diabetes mellitus

disease and this more marked in the mandibular than the maxillary arch. In other studies, it was still the incisors that were the most frequent teeth extracted due to periodontal disease but were more in the maxillary arch than the mandibular arch. ${ }^{[2,25]}$

The older age group that constitutes the majority of participants which is in tandem with previous study that reported worse periodontal status in that the older age group than the younger age group. ${ }^{[26]}$ It has been suggested that age is related to the incidence of periodontal destruction with periodontal pocketing as the principal mode of destruction. ${ }^{[27]}$ This study showed that onset of diabetes (self-reported age of diagnosis) between 41 and 70 years with a majority in middle age, a peak age at diagnosis in the sixth decade of life, and a mean age at diagnosis of $56.22 \pm 6.88$ years. This mean age of diagnosis of diabetes is higher than the mean age $(53 \pm 11$ years) previously reported in the same hospital ${ }^{[28]}$ and in the United States of America (46-
52 years). ${ }^{[29]}$ This may be explained by the fact that regular dental attendance is not a common practice as more than one-third of the participants was visiting for the first time, and also that tooth mobility from periodontal disease is of insidious onset and slowly progressive.

More males than females presented with a complaint of tooth mobility in this study suggesting that the male participants took their diabetic and oral conditions less seriously than their female counterpart resulting in more periodontal complication of diabetes in the male fold. Although not statistically significant, males had worse mean GI scores, probing depth, and periodontal status than females in this study.

The adverse effect of DM on the host response to plaque results in impaired gingival effect as noted in this study that gingival score which had mean as $1.60 \pm 0.08$ was significantly associated with age of the participants. DM has been reported to be among the systemic conditions that influence the host response to plaque. ${ }^{[30]}$ Worse periodontal status was found in more than one-third $(28.5 \%)$ of the participants which was higher than $15.4 \%$ reported by Umoh and Azodo ${ }^{[26]}$ among adult male population in Benin City. The prevalence of periodontal disease in patients with diabetes is reported to be higher than their nondiabetic counterparts. ${ }^{[6]}$ Due to more bacterial proliferation as a consequence of diminished primary defense against bacterial pathogens which are resultant effects of impaired chemotaxis, defective phagocytosis, and impaired adherence of PMNs and macrophages. ${ }^{[9]}$ Although there was inclusion of young adults in the compared study may also be an explanation as worse periodontal status increases with aging. The significantly more probing depth with aging and longer the duration 
of DM collaborates that DM accelerates the worsening of periodontal status with aging.

\section{CONCLUSION}

Data from this study revealed that age of diagnosis of diabetes with tooth mobility was higher than previously reported. The most mobile teeth and earliest teeth to become mobile were the mandibular incisors and Grade 1 severity constituted the majority. DM with tooth mobility exhibited gingival score and probing depth that had a variable significant association with demographic characteristics.

\section{Acknowledgment}

Part of this article was presented as an abstract in the $5^{\text {th }}$ Annual Scientific Conference $/ 40^{\text {th }}$ Anniversary of School of Dentistry, College of Medical Sciences, University of Benin in 2016.

Financial support and sponsorship

Nil.

\section{Conflicts of interest}

There are no conflicts of interest.

\section{REFERENCES}

1. Edward SH, Raffaele N. Diabetes mellitus. Present Knowledge in Nutrition. Washington DC: ILSI Press; 1996.

2. Shaw JE, Sicree RA, Zimmet PZ. Global estimates of the prevalence of diabetes for 2010 and 2030. Diabetes Res Clin Pract 2010;87:4-14.

3. Oyegbade O, Abioye Kuteyi E, Kolawole B, Ezeoma I, Bello I. Screening for diabetes mellitus in Nigerian family practice populations. S Afr Fam Pract 2007;49:15a-d.

4. Ojehanon PI, Akhionbare O. Prevalence of undiagnosed diabetes mellitus among dental patients in Edo state, Nigeria. J Med Biomed Sci 2006;5:24-8.

5. Opeodu OI, Adeyemi BF. Undiagnosed diabetes mellitus: A survey of dental outpatients in a tertiary hospital. Afr J Med Med Sci 2013;42:39-45

6. Löe H. Periodontal disease. The sixth complication of diabetes mellitus. Diabetes Care 1993;16:329-34.

7. Ervasti T, Knuuttila M, Pohjamo L, Haukipuro K. Relation between control of diabetes and gingival bleeding. J Periodontol 1985;56:154-7.

8. Bridges RB, Anderson JW, Saxe SR, Gregory K, Bridges SR. Periodontal status of diabetic and non-diabetic men: Effects of smoking, glycemic control, and socioeconomic factors. J Periodontol 1996;67:1185-92.

9. Rajkumar D, Subramanium G, Natarajan S, Mahalingam L, Thangavelu K. Diabetes and periodontal disease. J Pharm Bioallied Sci 2012;4:280-2.

10. Dombret J, Marcos E. Tooth mobility and containment. Rev Belge
Med Dent 1989;44:98-109.

11. Azodo CC, Ogbebor OG. Tooth Mobility in a Specialist Periodontology Clinic. Second University of Benin Annaual Resaerch Day (UBARD) Conference. Book of Proceedings; 2016. p. 119-20.

12. Miller SC. Textbook of Periodontia. Philadelphia: Blackiston Company; 1938. p. 92.

13. Serio FG. Clinical rationale for tooth stabilization and splinting. Dent Clin North Am 1999;43:1-6, v.

14. Azodo CC, Erhabor P. Management of tooth mobility in the periodontology clinic: An overview and experience from a tertiary healthcare setting. Afr J Med Health Sci 2016;15:50-7.

15. CochranWG. Sampling Techniques. $3^{\text {rd }}$ ed. New York: John Wiley and Sons; 1977.

16. Akhionbare O, Ojehanon PI, Ufomata DO, Jeboda SO. Periodontal treatment needs of Urban and rural populations in Edo State, Nigeria. Niger Dent J 2007;15:13-7.

17. Javed F, Näsström K, Benchimol D, Altamash M, Klinge B, Engström PE. Comparison of periodontal and socioeconomic status between subjects with type 2 diabetes mellitus and non-diabetic controls. J Periodontol 2007;78:2112-9.

18. Taylor GW, Burt BA, Becker MP, Genco RJ, Shlossman M, Knowler WC, et al. Non-insulin dependent diabetes mellitus and alveolar bone loss progression over 2 years. J Periodontol 1998;69:76-83.

19. Ong G. Periodontal disease and tooth loss. Int Dent J 1998;48 3 Suppl 1:233-8.

20. Sede MA, Ehizele AO. Oral diseases and diabetes: Nigerian medical and dental caregivers' perspective. Ann Afr Med 2015;14:193-9.

21. Arowojolu MO. Prevalence of periodontal pocketing and tooth mobility according to tooth types in Nigerians - A pilot study. Afr J Med Med Sci 2002;31:119-21.

22. Jaafar N, Razak IA, Nor GM. Trends in tooth loss due to caries and periodontal disease by tooth type. Singapore Dent J 1989;14:39-41.

23. Sayegh A, Hilow H, Bedi R. Pattern of tooth loss in recipients of free dental treatment at the University Hospital of Amman, Jordan. J Oral Rehabil 2004;31:124-30.

24. Upadhyaya C, Humagain M. The pattern of tooth loss due to dental caries and periodontal disease among patients attending dental department (OPD), Dhulikhel Hospital, Kathmandu University Teaching Hospital (KUTH), Nepal. Kathmandu Univ Med J 2009;7:59-62.

25. Shigli K, Hebbal M, Angadi GS. Relative contribution of caries and periodontal disease in adult tooth loss among patients reporting to the Institute of Dental Sciences, Belgaum, India. Gerodontology 2009;26:214-8.

26. Umoh AO, Azodo CC. Prevalence of gingivitis and periodontitis in an adult male population in Nigeria. Niger J Basic Clin Sci 2012;9:65-9.

27. Heitz-Mayfield LJ, Schätzle M, Löe H, Bürgin W, Anerud A, Boysen $\mathrm{H}$, et al. Clinical course of chronic periodontitis. II. Incidence, characteristics and time of occurrence of the initial periodontal lesion. J Clin Periodontol 2003;30:902-8.

28. Edo AE, Edo GO, Ohenhen OA, Ekhator NP, Ordiah WC. Age at diagnosis and duration of type 2 diabetes seen in Benin City, Nigeria. Afr J Diabetes Med 2015;23:18-9.

29. Koopman RJ, Mainous AG $3^{\text {rd }}$, Diaz VA, Geesey ME. Changes in age at diagnosis of type 2 diabetes mellitus in the United States, 1988 to 2000. Ann Fam Med 2005;3:60-3.

30. Mealey BL, Ocampo GL. Diabetes mellitus and periodontal disease. Periodontol 2000. 2007;44:127-53. 